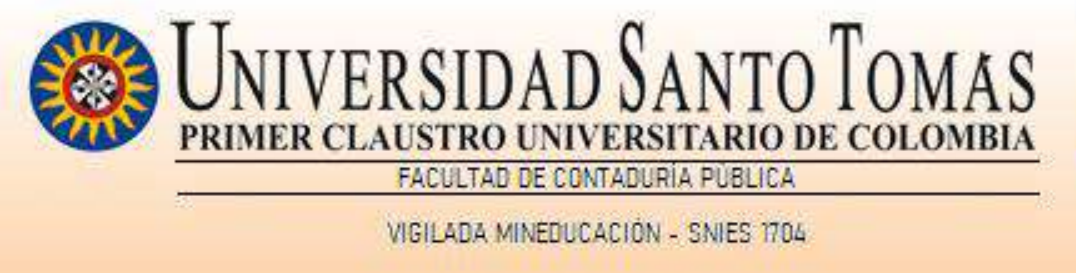

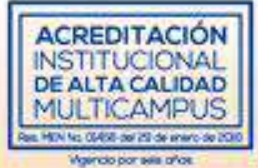

\title{
Semillero de Investigación en Educación y Teoría Contable
}

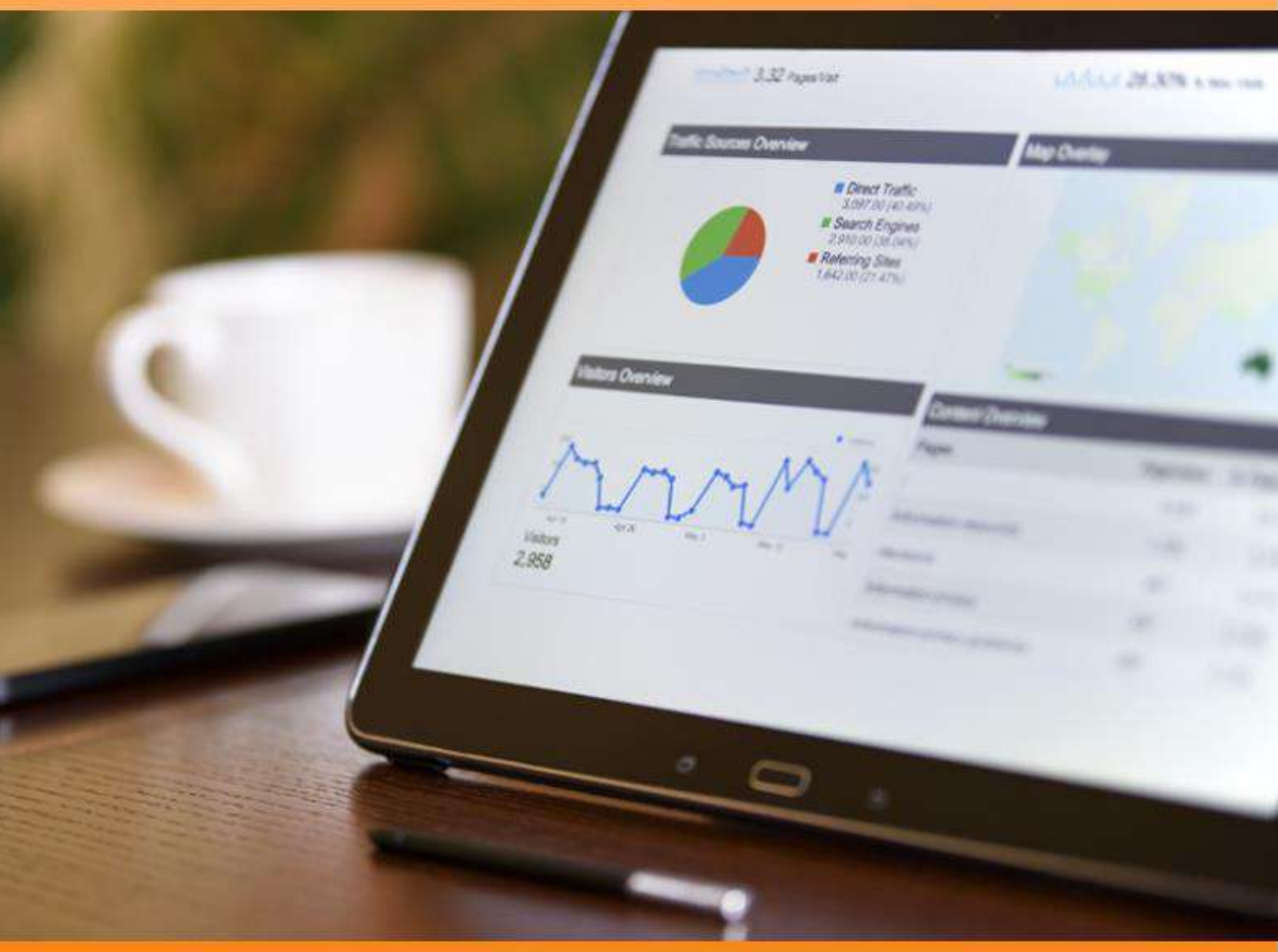

\section{Boletín SINETCO $\mathbf{N}^{\circ} \mathbf{1}$}

\author{
Julio 2020
}




\section{Contenido}

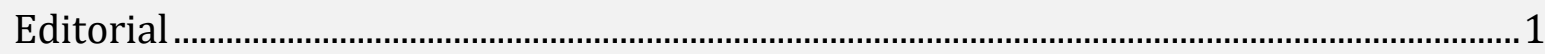

Asignación de facultades jurisdiccionales a la Contraloría General de la República........3

El "ser contable" desde la literatura ..........................................................................................

Análisis y revisión al nuevo Marco Conceptual 2018: Normas de información financiera

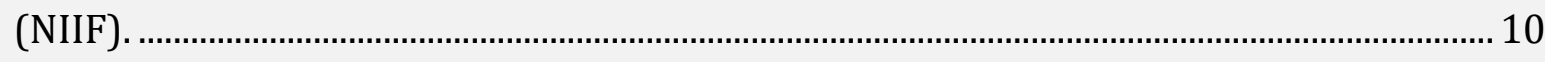

Manual de liquidación de los tipos de contratos ................................................................. 15

Cambios en las estructuras tributarias según las reformas que se dieron en las décadas

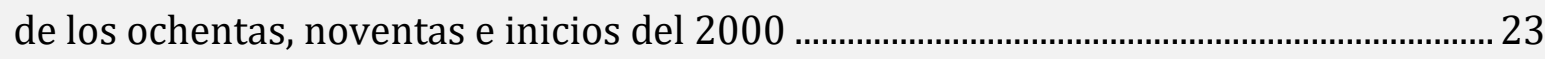

Realidad de los sistemas de gestión ambiental en las certificaciones ambientales en

Colombia.. 28

Nuevas tecnologías de la información y su relación con la contabilidad............................. 33 


\section{Editorial}

En el presente documento se compilan los trabajos de los estudiantes adscritos al Semillero de Investigación en Educación y Teoría Contable -SINETCO-, en las líneas activas de investigación de la Facultad de Contaduría Pública como parte de la propuesta de investigación formativa. En esta edición se tienen artículos derivados de reflexión y una guía de liquidación de contratos, adicionalmente está contenida la curiosidad y necesidad de expansión del conocimiento curricular ofrecido en su formación universitaria, asociada al creciente disentimiento sobre temáticas tendencia frente a la actuación del contable, sus responsabilidades, su aporte y la apropiación del conocimiento (Acosta y Valero, 2019).

¡Esperamos este espacio académico sea propicio para la difusión del conocimiento y preocupaciones de nuestros estudiantes!

Cordialmente, Julián David Sandoval Alarcón.

\section{Referencias}

Acosta, M., Barrio, S., \& Valero, G. (2019). Didácticas en la formación del contador público colombiano 2000-2015: una aproximación a partir de las publicaciones. Revista Activos, 16(31), 205 - 235. https://doi.org/10.15332/25005278/5320 